\title{
Short-span composite beam tests to evaluate stud resistances
}

1 Sebastian Nellinger Dr.-Ing

Project Engineer, ArcelorMittal Chair of Steel and Facade Engineering,

University of Luxembourg, Luxembourg, Luxembourg

2 Florian Eggert MEng

Project Engineer, Institute of Structural Design, University of Stuttgart, Stuttgart, Germany

3 Ulrike Kuhlmann Prof. Dr.-Ing.

Professor, Institute of Structural Design, University of Stuttgart, Stuttgart, Germany
4 Christoph Odenbreit Prof. Dr.-Ing.

Professor, ArcelorMittal Chair of Steel and Facade Engineering, University of Luxembourg, Luxembourg, Luxembourg (corresponding author: christoph.odenbreit@uni.lu)

5 Renata Obiala $\mathrm{PhD}$

Senior Researcher, ArcelorMittal Chair of Steel and Façade Engineering, University of Luxembourg, Luxembourg, Luxembourg
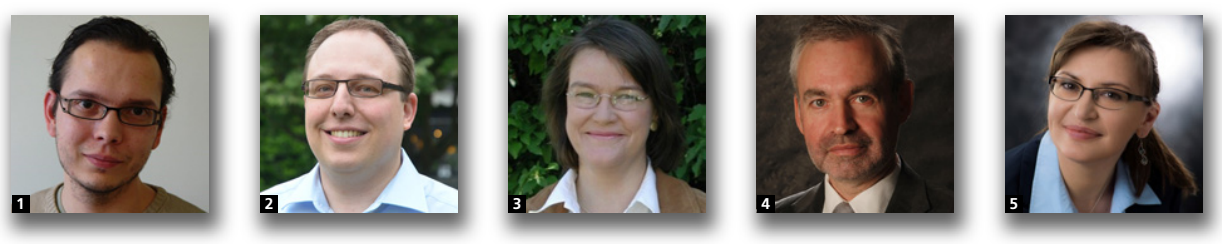

The results of a parametric study on ten short-span composite beam tests with small degrees of shear connection between 12 and $46 \%$ are presented. The beam tests were conducted using composite slabs with two modern forms of profiled steel sheeting. Important parameters of the shear connection, such as stud diameter, number of studs per rib, reinforcement pattern, welding procedure and concrete strength, were varied. All the test configurations were selected in accordance with a previously conducted study on the behaviour of shear connectors in push-out specimens. A comparison of the bending resistance of the beam tests and the calculated plastic bending resistance is presented. The shear connector resistances were taken either from the push-out test results or from the analytical methods of Konrad, EN 1994-1-1 and Nellinger. Evaluation of the push-out and beam test results showed that the current shear connector resistances in EN 1994-1-1 insufficiently predict the observed concrete failure modes and resistances in the presence of modern forms of steel decking. New approaches to the shear connector resistance proposed by Konrad and Nellinger led to more accurate predictions of the shear resistance of headed studs and the plastic bending resistance of the composite beam tests.

\begin{tabular}{|c|c|c|c|}
\hline & \multirow{2}{*}{$\begin{array}{l}H \\
h_{\mathrm{p}}\end{array}$} & \multirow{2}{*}{$\begin{array}{l}\text { thickness of composite slab } \\
\text { height of deck rib }\end{array}$} \\
\hline$A_{\mathrm{w}}$ & $\begin{array}{l}\text { Notation } \\
A_{\text {w }} \quad \text { effective area of weld collar }\end{array}$ & & \\
\hline$B$ & width of composite slab & $h_{\mathrm{sc}}$ & height of headed studs \\
\hline \multirow[t]{2}{*}{$b$} & correction of mean value according to EN 1990 & $h_{4}$ & height of weld collar \\
\hline & (DIN, 2010a) & $k_{\mathrm{t}}$ & reduction factor for studs in ribs of profiled sheeting \\
\hline \multirow[t]{2}{*}{$b_{\mathrm{m}}$} & width of deck rib at mid-height for trapezoidal & $L$ & span of composite beam \\
\hline & decking or at the top for re-entrant decking & $M_{6 \mathrm{~mm}}$ & bending moment of beam tests at $6 \mathrm{~mm}$ slip \\
\hline$b_{\max }$ & largest width of deck rib & $M_{\mathrm{PL}}$ & calculated plastic bending resistance \\
\hline$b_{\mathrm{o}}$ & width at top of rib & $M_{\mathrm{u}}$ & ultimate bending moment of beam test \\
\hline$d$ & diameter of headed studs & $N_{\mathrm{q}}$ & transverse compression force per deck rib \\
\hline$d_{3}$ & diameter of weld collar & $n_{\mathrm{r}}$ & number of studs per deck rib \\
\hline$E_{\mathrm{cm}}$ & Young's modulus of concrete & $P_{\mathrm{e}}$ & static shear resistance of headed studs in push-out \\
\hline$e$ & spacing between stud and edge of rib & & tests \\
\hline$e_{1}$ & eccentricity of stud to centreline of rib & $P_{\mathrm{Rm}}$ & mean shear resistance of headed studs \\
\hline$e_{\mathrm{s}}$ & transverse spacing between studs & $P_{\mathrm{u}}$ & ultimate test load applied to beam \\
\hline$f_{\mathrm{cm}}$ & mean cylinder strength of concrete & $P_{6 \mathrm{~mm}}$ & test load at $6 \mathrm{~mm}$ slip \\
\hline$f_{\mathrm{ctm}}$ & tensile strength of concrete & $s$ & slip \\
\hline$f_{\mathrm{u}}$ & mean tensile strength of stud material & $s_{\delta}$ & standard deviation of corrected mean value according \\
\hline$f_{\mathrm{uk}}$ & characteristic tensile strength of stud material & & to EN 1990 (DIN, 2010a) \\
\hline$f_{\mathrm{y}}$ & yield strength of steel section & $s_{\mathrm{e}, \mathrm{u}}$ & end slip of beam at ultimate load \\
\hline$G$ & self-weight of spreader beams & $s_{0 \cdot 95 \mathrm{Mu}}$ & end slip of beam when $95 \%$ of the ultimate load \\
\hline$g$ & self-weight of composite beam & & is reached \\
\hline
\end{tabular}



according to EN 1990 (DIN, 2010a)

$X \quad$ distance between support and critical section of beam

$\delta_{\mathrm{uk}} \quad$ displacement capacity of headed studs

$\eta \quad$ degree of shear connection

\section{Introduction}

New types of profiled decking have been developed for modern steel-concrete composite construction to maximise slab efficiency and provide large unpropped spans of the composite slab. The disadvantage is that, with modern deep or narrow deck ribs, the shear resistance of the headed studs is strongly reduced in comparison with cases with solid concrete slabs. This can lead to problems for the design of the supporting composite beams to satisfy the minimum degree of shear connection.

The design of modern long-span composite beams is often governed by the serviceability limit state. The stiffness that is required to satisfy the limits of deflection and vibration control defines the cross-section of the steel section of composite beams. At the ultimate limit state, the plastic load-bearing capacity is often not fully utilised. A fully plastic analysis of the shear connection is, in many cases, not allowed because the minimum degree of shear connection cannot be satisfied with the small shear resistance of the studs in profiled sheeting. In some cases it may even be impossible to provide a satisfactory shear resistance for elastic design and an uneconomic crosssection must be chosen to decrease the end slip sufficiently. Thus, a fully non-linear numerical analysis is required to achieve an economic design.

This paper presents the results of tests on ten short-span composite beams with modern profiled sheeting and low degrees of shear connection. Accompanying push-out tests were conducted to identify the shear connector behaviour. The paper addresses the application of plastic design of the shear interface to composite beams with less than the required minimum degree of shear connection according to EN 1994-1-1 (DIN, 2010b). In addition, it addresses the accurate prediction of the shear resistance of headed studs in modern profiled sheeting.

\section{Test programme}

\subsection{Short-span composite beam tests}

A series of ten short-span composite beam tests was conducted. The tests were designed to have low degrees of shear connection of about $12-46 \%$, based on the shear resistance of the studs determined from the conducted push-out tests. Two different types of steel decking with $58 \mathrm{~mm}$ and $80 \mathrm{~mm}$ deep ribs were used. For each type of decking, important parameters of the shear connection were varied. The parameters were the concrete cylinder strength, the stud diameter, the number of studs per rib, the welding method and the influence of transverse reinforcement below the head of the stud. Details of the beam tests conducted are shown in Table 1.

Considering the test setup, a four-point bending test was chosen to have an area of uniform bending moment at ultimate load (Figure 1). For the $58 \mathrm{~mm}$ deep decking, $5 \mathrm{~m}$ span beams were tested with point loads acting at a distance of $1.8 \mathrm{~m}$ from the supports (specimens 2-01 to 2-08 in Table 1). For the $80 \mathrm{~mm}$ deep decking, $6 \mathrm{~m}$ span beams with point loads acting $2 \cdot 25 \mathrm{~m}$ away from the support were tested (specimens 2-09 and 2-10 in Table 1).

\subsection{Push-out tests}

In advance of the beam tests, 58 push-out tests with three types of modern steel decking were conducted to investigate the behaviour of the shear studs separately (Eggert et al., 2014, Nellinger, 2015; Nellinger et al., 2014). The same types of $58 \mathrm{~mm}$ and $80 \mathrm{~mm}$ deep decking as in the beam tests and a $56 \mathrm{~mm}$ deep re-entrant decking were used. In the push-out tests, the same parameters were varied as in the beam tests. In

Table 1. Short-span composite beam tests

\begin{tabular}{|c|c|c|c|c|c|c|c|c|c|c|}
\hline \multirow[b]{2}{*}{$\begin{array}{l}\text { Beam } \\
\text { test ID }\end{array}$} & \multirow[b]{2}{*}{$L: \mathrm{mm}$} & \multirow[b]{2}{*}{$\eta^{a}$} & \multicolumn{2}{|c|}{ Steel beam } & \multicolumn{3}{|c|}{ Composite slab } & \multicolumn{3}{|c|}{ Headed studs } \\
\hline & & & Profile & $\begin{array}{c}f_{\mathrm{y}} \text { flange/web: } \\
\mathrm{N} / \mathrm{mm}^{2}\end{array}$ & $f_{\mathrm{cm}}: \mathrm{N} / \mathrm{mm}^{2}$ & $B / H / h_{p}: m m$ & $\begin{array}{l}\text { Number of } \\
\text { rebar layers }\end{array}$ & $n_{\mathrm{r}}$ & $d / h_{\mathrm{sc}}: \mathrm{mm}$ & $\begin{array}{l}\text { Through-deck } \\
\text { welded? }\end{array}$ \\
\hline $2-01$ & 5000 & 0.23 & IPE 300 & $383 / 418$ & $45 \cdot 2$ & $1250 / 130 / 58$ & 1 & 1 & $19 / 100$ & Yes \\
\hline $2-02$ & 5000 & 0.19 & IPE 300 & $383 / 418$ & $44 \cdot 3$ & $1250 / 130 / 58$ & 2 & 1 & $19 / 100$ & No \\
\hline $2-03$ & 5000 & $0 \cdot 46$ & IPE 300 & $383 / 418$ & $45 \cdot 4$ & $1250 / 130 / 58$ & 1 & 2 & 19/100 & Yes \\
\hline $2-04$ & 5000 & 0.41 & IPE 300 & $383 / 418$ & $44 \cdot 3$ & $1250 / 130 / 58$ & 1 & 2 & $19 / 100$ & No \\
\hline $2-05$ & 5000 & $0 \cdot 31$ & IPE 300 & $383 / 418$ & $41 \cdot 4$ & $1250 / 130 / 58$ & 1 & 1 & $22 / 100$ & No \\
\hline $2-06$ & 5000 & $0 \cdot 31$ & IPE 300 & $383 / 418$ & $41 \cdot 6$ & $1250 / 130 / 58$ & 2 & 1 & $22 / 100$ & No \\
\hline $2-07$ & 5000 & $0 \cdot 37$ & IPE 300 & $383 / 418$ & $64 \cdot 2$ & $1250 / 130 / 58$ & 2 & 1 & $22 / 100$ & No \\
\hline $2-08$ & 5000 & $0 \cdot 19$ & IPE 300 & $383 / 418$ & $63 \cdot 4$ & $1250 / 130 / 58$ & 2 & 1 & $19 / 100$ & No \\
\hline $2-09$ & 6000 & $0 \cdot 12$ & IPE 360 & $382 / 411$ & $48 \cdot 6$ & $1500 / 150 / 80$ & 1 & 1 & $19 / 125$ & Yes \\
\hline $2-10$ & 6000 & 0.21 & IPE 360 & $382 / 411$ & $49 \cdot 0$ & $1500 / 150 / 80$ & 1 & 2 & $19 / 125$ & Yes \\
\hline
\end{tabular}

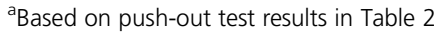


Table 2. Push-out tests to accompany the beam test results

\begin{tabular}{|c|c|c|c|c|c|c|c|c|c|c|}
\hline \multirow[b]{2}{*}{$\begin{array}{l}\text { Push } \\
\text { test ID }\end{array}$} & \multirow[b]{2}{*}{$\begin{array}{l}\text { Number of } \\
\text { tests in series }\end{array}$} & \multirow[b]{2}{*}{$\begin{array}{l}\text { Beam } \\
\text { test ID }\end{array}$} & \multicolumn{3}{|c|}{ Composite slab } & \multicolumn{3}{|c|}{ Headed studs } & \multicolumn{2}{|c|}{ Test results } \\
\hline & & & $f_{\mathrm{cm}}: \mathrm{N} / \mathrm{mm}^{2}$ & $H / h_{\mathrm{p}}: \mathrm{mm}$ & $\begin{array}{l}\text { Number of } \\
\text { reinforcement layers }\end{array}$ & $n_{r}$ & $d / h_{\mathrm{sc}}: \mathrm{mm}$ & $\begin{array}{l}\text { Through-deck } \\
\text { welded? }\end{array}$ & $P_{\mathrm{e}}: \mathrm{kN} / \mathrm{stud}$ & $\delta_{\mathrm{uk}}: \mathrm{mm}$ \\
\hline 2-01 & 3 & 2-01 & $42 \cdot 2$ & $150 / 58$ & 1 & 1 & $19 / 125$ & Yes & $62 \cdot 4$ & $>40$ \\
\hline 2-03 & 1 & 2-02 & $39 \cdot 7$ & $150 / 58$ & 2 & 1 & $19 / 125$ & No & $51 \cdot 6$ & $>40$ \\
\hline $2-04$ & 1 & $2-03$ & $40 \cdot 3$ & $150 / 58$ & 1 & 2 & $19 / 125$ & Yes & $61 \cdot 5$ & $6 \cdot 7$ \\
\hline $2-06$ & 3 & $2-05$ & $39 \cdot 3$ & $150 / 58$ & 1 & 1 & $11 / 125$ & No & $83 \cdot 1$ & $21 \cdot 3$ \\
\hline $1-03$ & 3 & $2-06$ & $42 \cdot 2$ & $150 / 58$ & 2 & 1 & $22 / 125$ & No & $83 \cdot 2$ & $36 \cdot 6$ \\
\hline 2-07 & 3 & $2-07$ & $46 \cdot 2$ & $150 / 58$ & 2 & 1 & $22 / 125$ & No & $99 \cdot 1$ & $7 \cdot 1$ \\
\hline $2-08$ & 1 & $2-08$ & $45 \cdot 8$ & $150 / 58$ & 2 & 1 & $19 / 125$ & No & $51 \cdot 0$ & $>40$ \\
\hline NR1-2 & 1 & $2-09$ & $45 \cdot 7$ & $150 / 80$ & 1 & 1 & $19 / 125$ & Yes & $67 \cdot 5$ & $12 \cdot 2$ \\
\hline $1-10-1$ & 1 & $2-10$ & $42 \cdot 6$ & $150 / 80$ & 1 & 2 & $19 / 125$ & Yes & $40 \cdot 6$ & $23 \cdot 2$ \\
\hline
\end{tabular}

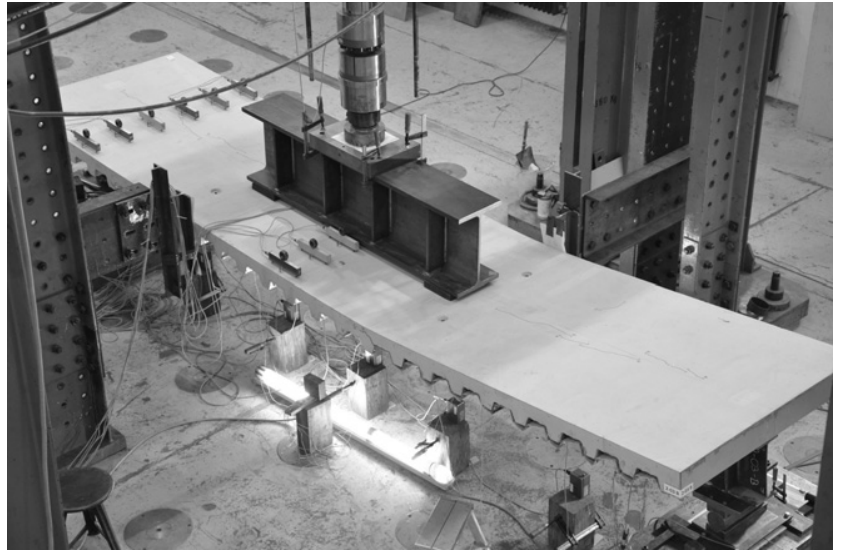

Figure 1. Test setup of the composite beam tests (specimen 2-03 is shown)

addition, the influence of transverse compression on the shear interface was investigated. Table 2 shows the results of the push-out tests that were used for the design and evaluation of the composite beam tests.

\section{Test results}

\subsection{Load-displacement behaviour and failure modes of headed studs in profiled sheeting}

Using modern forms of profiled sheeting, the load-slip behaviour of headed studs in the ribs of deep steel decking can be differentiated into two load-bearing mechanisms according to the push-out test results (Nellinger, 2015).

The first load-bearing mechanism occurs for headed studs with a large embedment depth of the head of the stud into the concrete above the rib, typically reaching the design resistance because of rib punch-though failure (Lungershausen, 1988); see Figure 2(b). This load-bearing mechanism is characterised by the development of S-shaped stud deformation, as shown in Figure 2(c). The final failure of the shear connection occurs at a very large displacement when a large tension force develops in the stud shank because of geometric non-linearity. The failure modes are then either stud rupture or concrete pull-out. This behaviour was typical for the push-out tests with $58 \mathrm{~mm}$ and $56 \mathrm{~mm}$ deep decking. A representative load-slip curve is shown in Figure 2(a).

The second load-bearing mechanism occurs for headed studs with a too small embedment into the concrete above the rib. The short studs reach their resistance when rib pry-out failure occurs. This failure mode occurs at a small slip and is related to the bending resistance of the concrete rib. A typical failure surface is shown in Figure 3(c). The post-failure behaviour strongly depends on friction between the failed concrete cone and the concrete topping and could be strongly improved by transverse compression (Nellinger, 2015). The deformed studs typically develop a single curvature, as shown in Figure 3(b). Using pairs of studs per rib led to just a $10-20 \%$ increase of the shear resistance per rib, which is significantly smaller than the $40-60 \%$ increase assumed in EN 1994-1-1 (DIN, 2010b). Rib pry-out failure was typical for the push-out tests with $80 \mathrm{~mm}$ deep decking. Figure 3(a) shows a representative load-slip curve.

For both types of load-bearing behaviour, the characteristic slip capacity $\delta_{\mathrm{uk}}$, shown in Table 2, was larger than the $6 \mathrm{~mm}$ requirement of EN 1994-1-1 (DIN, 2010b).

\subsection{Results of short-span composite beam tests}

Many of the rules in EN 1994-1-1 (DIN, 2010b) for the design of composite beams were based on tests of shear connectors in solid slabs. Headed studs in solid slabs show a more brittle failure and smaller displacement capacity than studs in the ribs of profiled sheeting. The large slip of the shear connectors that occurs in a plastic design of the shear interface could lead to a zipper-like failure of the shear connectors. EN 1994-1-1 (DIN, $2010 \mathrm{~b}$ ) prevents this failure by requiring a minimum degree of shear connection and ductile shear connectors. The current rules for the minimum degree of shear connection are empirical (Aribert, 1997). The equations were calibrated based on non-linear analysis of propped composite beams. The minimum degree of shear connection was defined in such a way that $95 \%$ of the fully plastic bending resistance is reached at a limiting slip of $6 \mathrm{~mm}$. The current equations for 
Structures and Buildings

Volume 171 Issue SB1
Short-span composite beam tests

to evaluate stud resistances

Nellinger, Eggert, Kuhlmann, Odenbreit

and Obiala

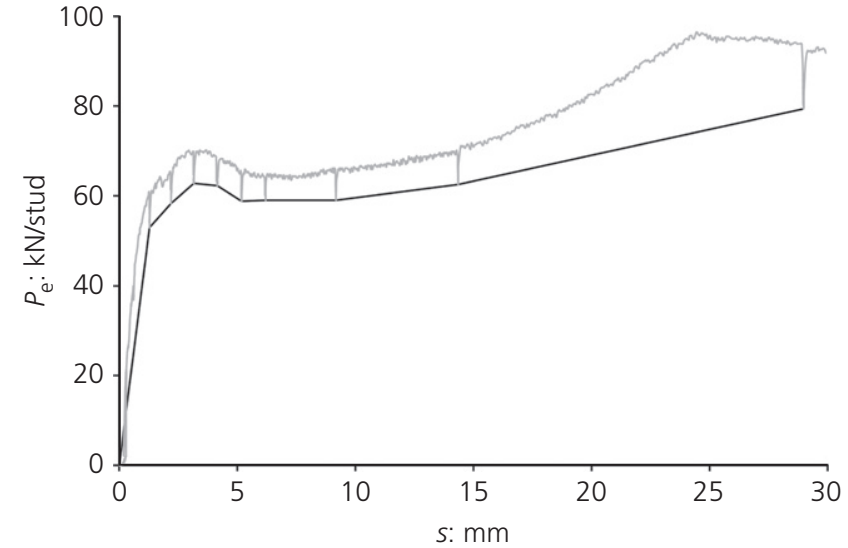

(a)

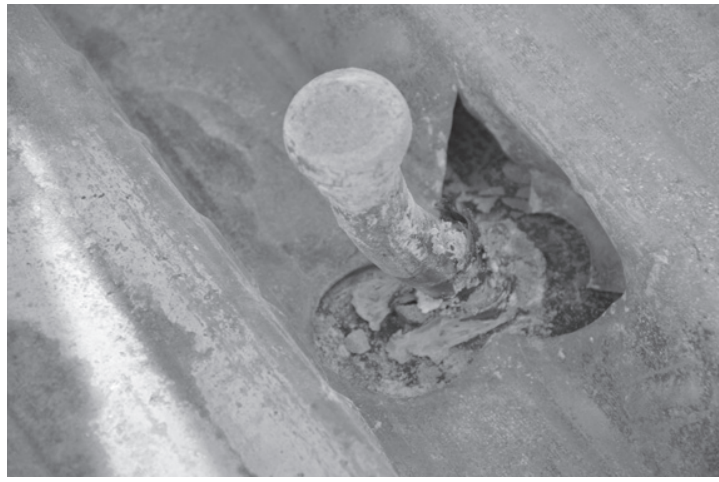

(b)

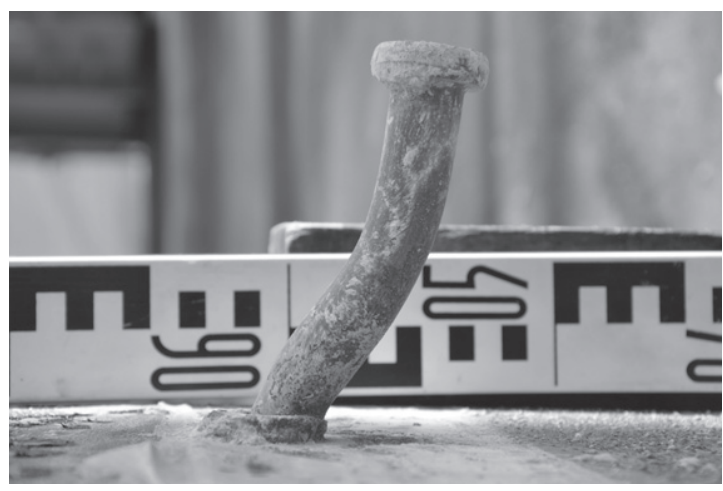

(c)

Figure 2. Rib punch-through failure in $58 \mathrm{~mm}$ deep decking: (a) typical load-slip curve; (b) rib punch-through; (c) stud deformation

the minimum degree of shear connection are best fits to the numerical obtained results.

EN 1994-1-1 (DIN, 2010b) gives the minimum degree of shear connection for composite beams with profiled sheeting by Equations 1 and 2. Equation 1 gives a calculated minimum degree of shear connection of $26 \%$ for the $5 \mathrm{~m}$ span beam tests and $29 \%$ for the $6 \mathrm{~m}$ span beam tests. In both cases, the minimum cut-off value of $40 \%$ must be satisfied. The application

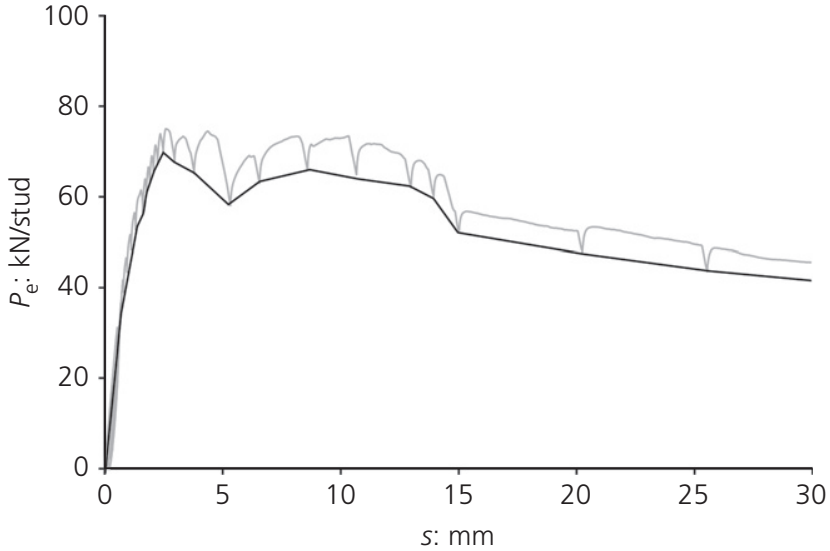

(a)

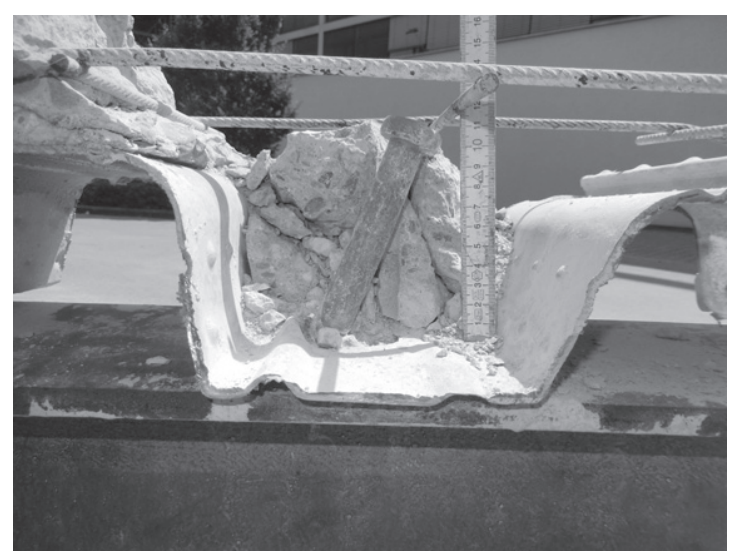

(b)

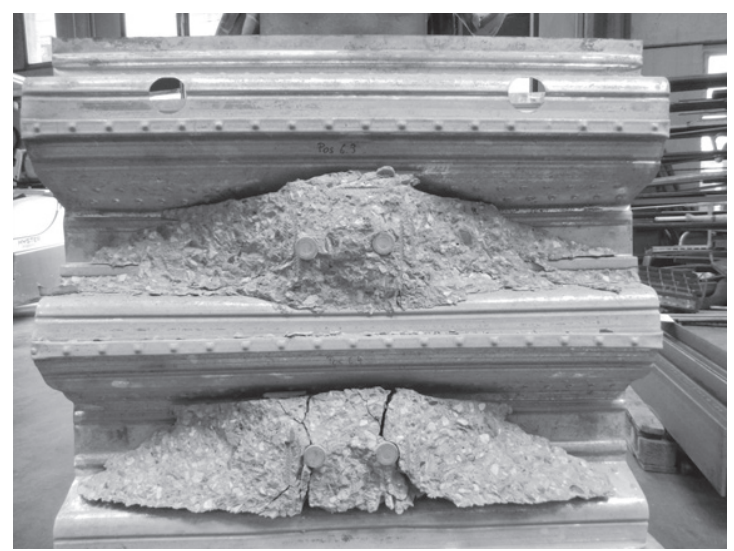

(c)

Figure 3. Rib pry-out failure in $80 \mathrm{~mm}$ deep decking: (a) typical load-slip curve without transverse compression; (b) stud deformation; (c) failure surface of the concrete

of Equations 1 and 2 is limited by several restrictions that none of the conducted composite beam tests satisfied. The tests with $58 \mathrm{~mm}$ deep decking had a ratio $b_{\mathrm{m}} / h_{\mathrm{p}}=1.4$ and thus did not satisfy the requirement $b_{\mathrm{m}} / h_{\mathrm{p}} \geq 2$. Test with $80 \mathrm{~mm}$ deep decking exceeded the restriction $h_{\mathrm{p}} \leq 60 \mathrm{~mm}$. Furthermore, for through-deck welding, pairs of studs per rib 


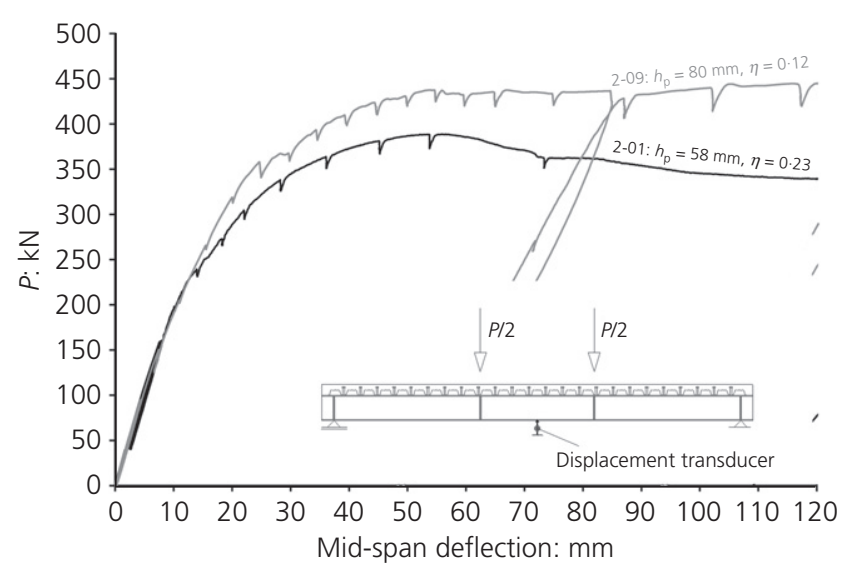

Figure 4. Typical load-displacement curves of composite beam tests

and $22 \mathrm{~mm}$ diameter studs are not allowed. EN 1994-1-1 (DIN, 2010b) states

1. $L \leq 25 \mathrm{~m}: \min \eta=1-\frac{355}{f_{\mathrm{y}}}(1 \cdot 0-0 \cdot 04 L) \geq 0 \cdot 4$

2. $L>25 \mathrm{~m}: \min \eta=1$

For composite beams with solid slabs, EN 1994-1-1 requires the minimum degree of shear connection to satisfy Equations 3 and 4.

3. $L \leq 25 \mathrm{~m}: \min \eta=1-\frac{355}{f_{\mathrm{y}}}(0.75-0.03 L) \geq 0.4$

4. $L>25 \mathrm{~m}: \min \eta=1$

This results in a required minimum degree of shear connection of $44 \%$ for beams of $5 \mathrm{~m}$ span and $47 \%$ for beams of $6 \mathrm{~m}$ span. Based on the resistance of headed studs from push-out tests, the composite beams had degrees of shear connection between $12 \%$ and $46 \%$, as shown in Table 1 . Only specimen 2-03 satisfied the required minimum degree of shear connection.

All the tests showed ductile load-deflection behaviour. Examples of load-displacement graphs from the beam tests are shown in Figure 4. The ultimate load was reached at a deflection of about span/100. The end slip at ultimate load was between $2.5 \mathrm{~mm}$ and $7 \cdot 1 \mathrm{~mm}$. Considering the self-weight of the composite beam and the loading rig, the bending moment acting at the critical section of the composite beam can be calculated according to Equation 5. The obtained bending moment at ultimate load $\left(M_{\mathrm{u}}\right)$ and at $6 \mathrm{~mm}$ end slip $\left(M_{6 \mathrm{~mm}}\right)$ are shown in Table 3.

5. $M_{\mathrm{u}}=\frac{g}{2} X(L-X)+\frac{G+P_{\mathrm{u}}}{2} X$

At $95 \%$ of ultimate load, all beams had an end slip smaller than $6 \mathrm{~mm}$. At $6 \mathrm{~mm}$ end slip, only beam 2-04 showed a decrease of the test load $90 \%$ of ultimate load. All other beams reached more than $98 \%$ of ultimate load at $6 \mathrm{~mm}$ end slip.

\section{Shear resistance of headed studs}

\subsection{Procedure in EN 1994-1-1 (DIN, 2010b)}

The rules for the shear resistance of headed studs in profiled sheeting were empirically derived and a reduction factor is applied to the shear resistance of studs in solid slabs. The mean shear resistance is calculated as the smaller of Equations 6 and 7 (Roik et al., 1989). The reduction factor is given by Equation 8. The upper limits for the reduction factor $\left(k_{\mathrm{t}, \max }\right)$ are given in Table 4 . The considered parameters of the decking and studs are shown in Figure 5.

For steel failure

6. $\quad P_{\mathrm{Rm}}=k_{\mathrm{t}} 1 \cdot 00 f_{\mathrm{u}} \pi d^{2} / 4$

For concrete failure

7. $\quad P_{\mathrm{Rm}}=k_{\mathrm{t}} 0 \cdot 374 \alpha d^{2} \sqrt{f_{\mathrm{cm}} E_{\mathrm{cm}}}$

The reduction factor is given by

8. $\quad k_{\mathrm{t}}=\frac{0 \cdot 7}{\sqrt{n_{\mathrm{r}}}} \cdot \frac{b_{\mathrm{m}}}{h_{\mathrm{p}}}\left(\frac{h_{\mathrm{sc}}}{h_{\mathrm{p}}}-1\right) \leq k_{\mathrm{t}, \max }$

where

$$
\begin{array}{ll}
\alpha=0 \cdot 2\left(\frac{h_{\mathrm{sc}}}{d}+1\right) & \text { for } \quad 3 \leq h_{\mathrm{sc}} / d \leq 4 \\
\alpha=1 & \text { for } \quad h_{\mathrm{sc}} / d>4
\end{array}
$$

\subsection{Procedure of Konrad (2011)}

The welding position of the stud has a significant influence on the shear resistance. A new formula to consider this influence 
Table 3. Bending resistances achieved in short-span composite beam tests

\begin{tabular}{|c|c|c|c|c|c|c|c|c|c|c|c|c|}
\hline \multirow[b]{2}{*}{ Test } & \multirow[b]{2}{*}{$\begin{array}{c}X: \\
\mathbf{m m}\end{array}$} & \multirow[b]{2}{*}{$\begin{array}{c}g: \\
k N / m\end{array}$} & \multirow[b]{2}{*}{$\begin{array}{l}\text { G: } \\
\text { kN }\end{array}$} & \multirow[b]{2}{*}{$\begin{array}{l}P_{\mathrm{u}}: \\
\mathrm{kN}\end{array}$} & \multirow[b]{2}{*}{$\underset{\mathrm{kN}}{P_{6 \mathrm{~mm}}:}$} & \multirow[b]{2}{*}{$\begin{array}{c}M_{\mathrm{u}}: \\
\mathrm{kN} \cdot \mathrm{m}\end{array}$} & \multirow[b]{2}{*}{$\begin{array}{l}M_{6 \mathrm{~mm}}: \\
\mathrm{kN} \cdot \mathrm{m}\end{array}$} & \multirow[b]{2}{*}{$M_{6 \mathrm{~mm}} / M_{\mathrm{u}}$} & \multirow[b]{2}{*}{$\begin{array}{l}s_{\mathrm{e}, \mathrm{u}}: \\
\mathrm{mm}\end{array}$} & \multirow[b]{2}{*}{$\begin{array}{c}s_{0.95 \mathrm{Mu}}: \\
\mathrm{mm}\end{array}$} & \multicolumn{2}{|c|}{$\eta / \min \eta$} \\
\hline & & & & & & & & & & & Equation 1 & Equation 3 \\
\hline 2-01 & 1800 & 3.4 & 3.5 & $186 \cdot 7$ & $185 \cdot 8$ & $346 \cdot 8$ & $345 \cdot 2$ & 1.00 & $5 \cdot 8$ & $3 \cdot 2$ & 0.88 & 0.52 \\
\hline $2-02$ & 1800 & $3 \cdot 4$ & 3.5 & 188.7 & 187.6 & $350 \cdot 3$ & $348 \cdot 3$ & 0.99 & $6 \cdot 3$ & $2 \cdot 8$ & 0.73 & 0.43 \\
\hline $2-03$ & 1800 & $3 \cdot 4$ & 3.5 & $187 \cdot 2$ & 187 & $347 \cdot 6$ & $347 \cdot 3$ & 1.00 & $5 \cdot 1$ & $2 \cdot 4$ & 1.76 & 1.05 \\
\hline $2-04$ & 1800 & $3 \cdot 4$ & 3.5 & $217 \cdot 6$ & 195 & $401 \cdot 7$ & $361 \cdot 5$ & 0.90 & $2 \cdot 5$ & $2 \cdot 3$ & 1.57 & 0.93 \\
\hline $2-05$ & 1800 & $3 \cdot 4$ & 3.5 & 194.5 & $193 \cdot 5$ & $360 \cdot 6$ & 358.9 & 1.00 & $5 \cdot 3$ & $2 \cdot 6$ & $1 \cdot 19$ & 0.70 \\
\hline $2-06$ & 1800 & $3 \cdot 4$ & 3.5 & 201.7 & 199 & 373.4 & 368.7 & 0.99 & 4.9 & $3 \cdot 1$ & $1 \cdot 19$ & 0.70 \\
\hline $2-07$ & 1800 & $3 \cdot 4$ & 3.5 & $205 \cdot 5$ & $203 \cdot 5$ & $380 \cdot 1$ & $376 \cdot 7$ & 0.99 & 4.6 & 2.6 & 1.42 & 0.84 \\
\hline $2-08$ & 1800 & $3 \cdot 4$ & 3.5 & $197 \cdot 7$ & 197 & $366 \cdot 4$ & $365 \cdot 1$ & 1.00 & $6 \cdot 1$ & $2 \cdot 9$ & 0.73 & 0.43 \\
\hline $2-09$ & 2250 & 4.9 & 4.0 & $425 \cdot 0$ & $417 \cdot 1$ & $503 \cdot 3$ & $494 \cdot 4$ & 0.98 & $7 \cdot 1$ & 5.0 & 0.41 & 0.26 \\
\hline $2-10$ & 2250 & 4.9 & 4.0 & $466 \cdot 8$ & $459 \cdot 9$ & $550 \cdot 3$ & $542 \cdot 6$ & 0.99 & $6 \cdot 6$ & $3 \cdot 2$ & 0.72 & 0.45 \\
\hline
\end{tabular}

Table 4. Upper limits $\left(k_{\mathrm{t}, \text { max }}\right)$ for the reduction factor $k_{\mathrm{t}}$

\begin{tabular}{cccc}
$\boldsymbol{n}_{\mathbf{r}}$ & $\boldsymbol{t} \mathbf{\mathbf { ~ } \mathbf { m m }}$ & $\begin{array}{c}\text { Through-deck welded } \\
\boldsymbol{d} \leq \mathbf{2 0} \mathbf{~} \mathbf{m m}\end{array}$ & $\begin{array}{c}\text { Holes provided in sheeting } \\
\mathbf{1 9} \mathbf{~} \mathbf{m m} \leq \boldsymbol{d} \leq \mathbf{2 2} \mathbf{~ m m}\end{array}$ \\
\hline 1 & $\leq 1.0$ & 0.85 & 0.75 \\
1 & $>1.0$ & 1.00 & 0.75 \\
2 & $\leq 1.0$ & 0.70 & 0.60 \\
2 & $>1.0$ & 0.80 & 0.60 \\
\hline
\end{tabular}

was developed by Konrad (2011) along with new equations for the shear resistance of studs in solid slabs. The new reduction factors were based on correlation curves identified from nonlinear analysis.

The mean shear resistance of studs in profiled sheeting is the smaller value of Equations 9 and 10. The reduction factor depends on the welding position and is given by Equations 11 and 12. These are simplified equations for the case $h_{\mathrm{sc}} / h_{\mathrm{p}} \geq 1 \cdot 56$. More complex equations for this case and shorter studs were also proposed. According to the spacing $e$, shown in Figure 5, the shear stud position is given as

$e \leq 55 \mathrm{~mm}$ - unfavourable position

$55 \mathrm{~mm}<e \leq 100 \mathrm{~mm}$ - mid-position

$e>100 \mathrm{~mm}$ - favourable position

Different to EN 1994-1-1 (DIN, 2010b), the reduction factor is applied only for concrete failure and it is assumed that the resistance in the case of stud rupture is not affected by the decking.

For steel failure

9. $\quad P_{\mathrm{Rm}}=39 \cdot 85 A_{\mathrm{w}} f_{\mathrm{cm}}^{2 / 3}+0 \cdot 59 f_{\mathrm{u}} d^{2}$

For concrete failure

10. $P_{\mathrm{Rm}}=k_{\mathrm{t}}\left(39 \cdot 85 A_{\mathrm{w}} f_{\mathrm{cm}}^{2 / 3}+3 \cdot 75 d^{2} f_{\mathrm{cm}}^{1 / 3} f_{\mathrm{u}}^{1 / 3}\right)$

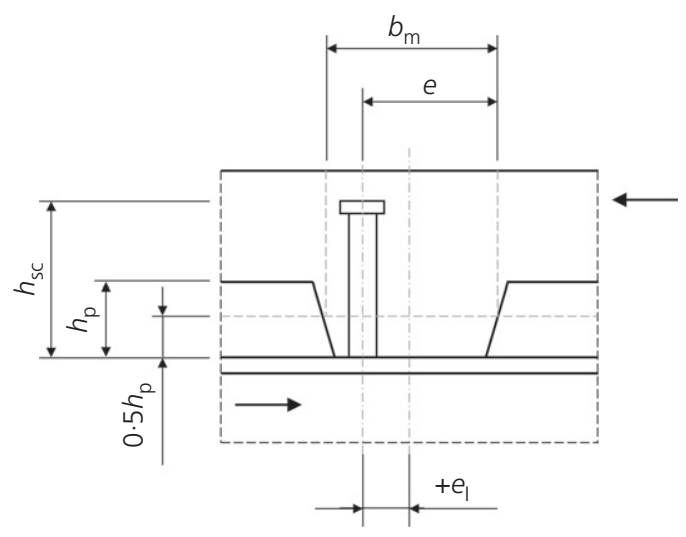

(a)

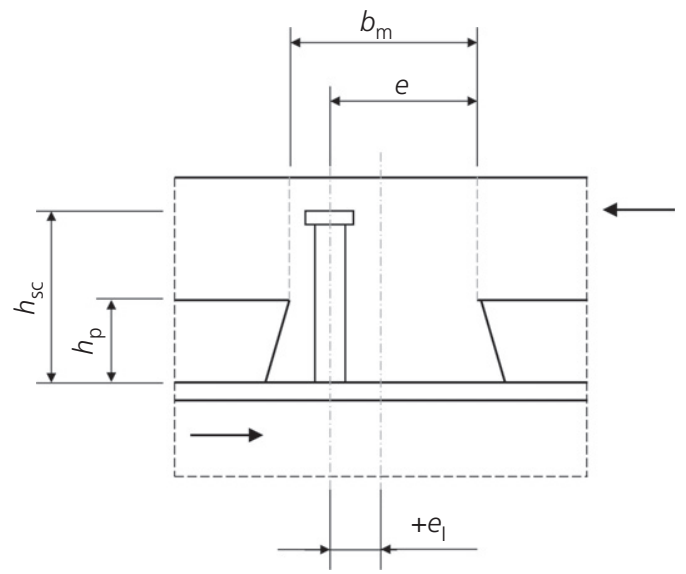

(b)

Figure 5. Headed studs in profiled sheeting: (a) trapezoidal decking; (b) re-entrant decking

For an unfavourable position

11. $k_{\mathrm{t}}=k_{\mathrm{n}}\left(0 \cdot 317 \frac{b_{\mathrm{m}}}{h_{\mathrm{p}}}+0.06\right) \leq 0 \cdot 8$ 
and for a favourable/mid position

12. $k_{\mathrm{t}}=k_{\mathrm{n}} k_{\mathrm{Tr}} k_{\mathrm{w}}\left(k_{\mathrm{e}} 0.042 \frac{b_{\mathrm{m}}}{h_{\mathrm{p}}}+0.663\right) \leq 1 \cdot 0$

$A_{\mathrm{w}}=0 \cdot 5 d_{3} h_{4}$ is the effective area of the weld collar, $k_{\mathrm{n}}=1$ for single studs per rib, $k_{\mathrm{n}}=0.8$ for pairs of studs per rib, $k_{\mathrm{Tr}}=1$ for trapezoidal decking, $k_{\mathrm{Tr}}=1.25$ for re-entrant decking, $k_{\mathrm{w}}=1$ for through-deck welded studs, $k_{\mathrm{w}}=0.9$ when holes are provided in the sheeting, $k_{\mathrm{e}}=1$ for studs in the mid-position and $k_{\mathrm{e}}=2$ for studs in a favourable position.

\subsection{Procedure of Nellinger (2015)}

Based on the results of the conducted push-out tests with modern profiled sheeting, new equations for the shear resistance of headed studs in profiled sheeting were developed to describe the observed failure modes and stud deformations (Nellinger, 2015).

Different to the methods of EN 1994-1-1 (DIN, 2010b) and Konrad (2011), the equations are based on simple mechanical models. The resistance for steel failure, shown in Equation 13, is the resultant of a plastic shear-stress distribution in the stud shank. The resistance for concrete failure, shown in Equation 14, is the elastic resistance of the concrete rib in bending and compression plus the plastic bending resistance of the shear stud. This equation differentiates the two typical load-bearing mechanisms (see Figures 2 and 3) by assuming either single- or double-curvature of the stud in dependency of the embedment depth of the head of the stud. The mean shear resistance of headed studs in profiled sheeting is then the smaller of Equations 13 and 14.

For steel failure

13. $P_{\mathrm{Rm}}=1 \cdot 26 \frac{f_{\mathrm{uk}}}{\sqrt{3}} \pi d^{2} / 4$

For concrete failure

14. $P_{\mathrm{Rm}}=1 \cdot 23\left(\frac{\left[\left(\alpha_{\mathrm{ct}} f_{\mathrm{ctm}}+\left(N_{\mathrm{q}}+N_{\mathrm{sc}}\right) / A\right)\right] W+N_{\mathrm{sc}} e_{1}}{h_{\mathrm{p}} n_{r}}+\frac{n_{\mathrm{y}} M_{\mathrm{PL}}}{h_{\mathrm{s}}-d / 2}\right)$

where $\alpha_{\mathrm{ct}}=0 \cdot 85$

$$
N_{\mathrm{sc}}=0 \cdot 1 n_{\mathrm{r}} f_{\mathrm{uk}} \pi d^{2} / 4
$$

$$
A=\left[2 \cdot 4 h_{\mathrm{sc}}+\left(n_{\mathrm{r}}-1\right) e_{\mathrm{s}}\right] b_{\max }
$$

$$
W=\frac{1}{6}\left[2 \cdot 4 h_{\mathrm{sc}}+\left(n_{\mathrm{r}}-1\right) e_{\mathrm{s}}\right] \frac{b_{\max }^{3}}{b_{\mathrm{o}}}
$$

$$
n_{\mathrm{y}}=2 \text { for } h_{\mathrm{sc}} \geq h_{\mathrm{p}}+2 d \sqrt{n_{\mathrm{r}}}
$$

$$
n_{\mathrm{y}}=1 \text { for } h_{\mathrm{sc}}<h_{\mathrm{p}}+2 d \sqrt{n_{\mathrm{r}}}
$$

$$
M_{\mathrm{pl}}=f_{\mathrm{uk}} d^{3} / 6
$$

$$
h_{\mathrm{s}}=\frac{\beta h_{\mathrm{sc}}+\left[\left(n_{\mathrm{r}}-1\right)\left(h_{\mathrm{p}}+h_{\mathrm{sc}}\right) e_{\mathrm{s}}\right] / 4 \cdot 8 h_{\mathrm{sc}}}{1+\left(\left(n_{\mathrm{r}}-1\right) e_{\mathrm{s}} / 2 \cdot 4 h_{\mathrm{sc}}\right)}
$$

and $\beta=0.45$ for trapezoidal decking and $\beta=0.41$ for re-entrant decking.

\section{Analysis of push-out test results}

A comparison of the push-out test results with the calculated mean shear resistances is shown in Figure 6. The empirical formulae of EN 1994-1-1 (DIN, 2010b) over-predict the resistance of the push-out tests by $42 \%$, based on the correction factor $b$, which was determined according to EN 1990 (DIN, 2010a).

For the tests with $58 \mathrm{~mm}$ deep decking, the width of the rib was $b_{\mathrm{m}}=82 \mathrm{~mm}$. For the centric welding position of the studs, this led to the dimension $e=41 \mathrm{~mm}$. According to Konrad (2011), the studs were welded in an unfavourable position.

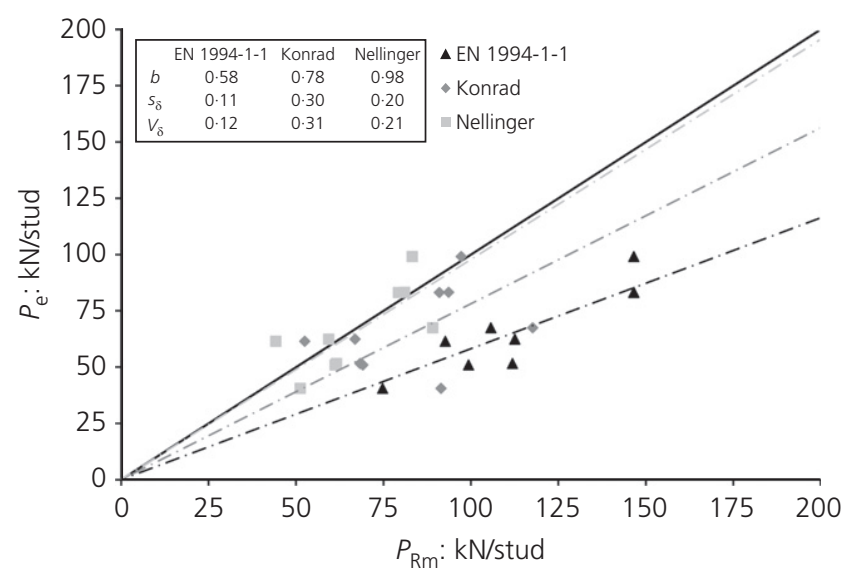

Figure 6. Comparison of shear resistance in push-out tests $\left(P_{\mathrm{e}}\right)$ with calculated shear resistance $\left(P_{\mathrm{Rm}}\right)$ according to the approaches of EN 1994-1-1 (DIN, 2010b), Konrad (2011) and Nellinger (2015) 
This indicates that the formulae of EN 1994-1-1 (DIN, 2010b) cannot be easily applied to modern forms of steel decking because the influence of the welding position is not covered.

For tests with $80 \mathrm{~mm}$ deep decking, the observed failure mode was rib pry-out failure. Considering the minimum embedment depth of the head of the stud of two diameters, the formulae of EN 1994-1-1 (DIN, 2010b) had been calibrated for rib punch-through failure. This explains the over-prediction of the shear resistance for rib pry-out failure.

In addition, only for the tests with $80 \mathrm{~mm}$ deep decking was the reduction factor according to Equation 8 decisive. For the tests with $58 \mathrm{~mm}$ deep decking, the limitation $k_{\mathrm{t}, \max }$ had to be applied. This limitation considers a beneficial influence of through-deck welding that could not be verified by the results of the test presented here. In fact, macro-sections of studs showed that the quality of the welding may have worsened when welding through the decking (see Figure 7).

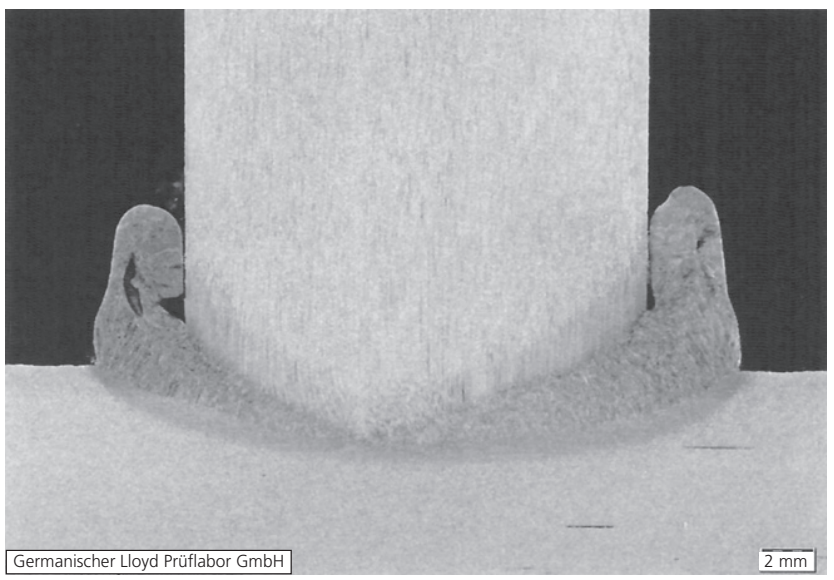

(a)

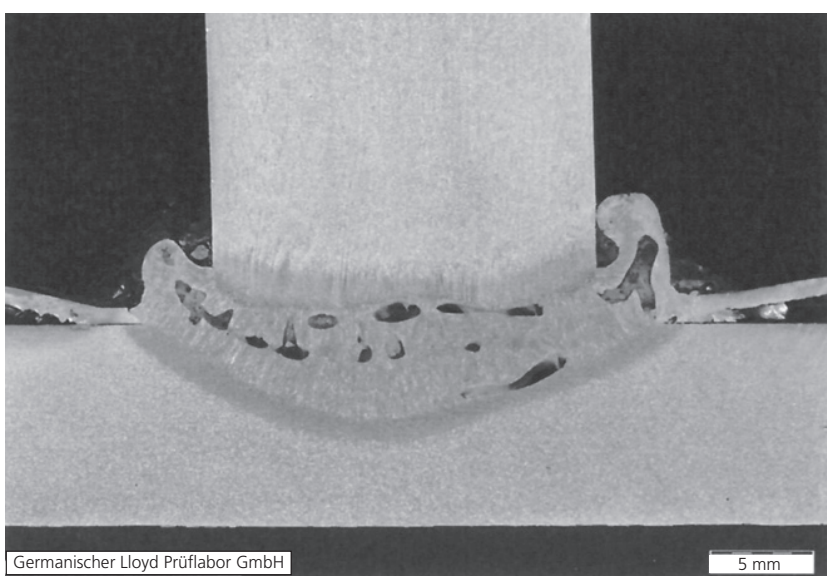

(b)

Figure 7. Macro-sections of welded studs: (a) welded directly to the flange of the beam; (b) welded through the steel decking
The Konrad formulae over-predict the mean shear resistance by $22 \%$. This is a significant improvement compared with EN 1994-1-1 (DIN, 2010b). In particular, rib pry-out failure in $80 \mathrm{~mm}$ deep decking was over-estimated by $56-43 \%$. This failure mode occurred when using $125 \mathrm{~mm}$ long studs, resulting in a ratio $h_{\mathrm{sc}} / h_{\mathrm{p}}=125 / 80=1 \cdot 56$, which is the absolute lower limit of the presented formulae. It is assumed that the formulae would have resulted in more accurate predictions of the shear resistance if the studs had been long enough to ensure rib punch-through failure. If only push-out tests with $58 \mathrm{~mm}$ deep decking are considered, the correction factor improves to $b=0 \cdot 91$. The coefficient of variation is, in this case, $V_{\delta}=0 \cdot 16$. The eight tests with $58 \mathrm{~mm}$ deep decking were predicted using Equation 11, which was proposed for through-deck welded studs. However, six out of the eight tests had holes provided in the decking. Therefore, the factor $b=0.91$ corresponds to the not yet considered influence of the welding method assumed by the factor $k_{\mathrm{w}}$.

The mechanical model of Nellinger (2015) gives the closest prediction of the mean shear resistance and over-predicts it by only $3 \%$. This is the newest of the presented models and was developed and calibrated based on the results of the presented push-out tests. The obtained coefficient of variation $V_{\delta}=0 \cdot 21$ is relatively large in comparison with the other methods. However, the model is capable of considering the two different failure modes - rib pry-out and rip punch-through - and the influence of the welding position in one equation. The large number of influencing parameters covered in a single equation explains the larger coefficient of variation compared with the more differentiated solutions of Konrad.

The comparisons showed that predicting the mean shear resistance according to EN 1994-1-1 leads to unsafe results for the investigated modern forms of profiled sheeting. The methods proposed by Konrad and Nellinger both result in good predictions of the shear resistance for rib punch-through failure. The Konrad method over-predicts the resistance in the case of rib pry-out failure because this failure was not considered in the development of the formulae. The model of Nellinger considers rib pry-out failure by the number of yield hinges in the stud shank.

\section{Analysis of composite beam test results}

6.1 Plastic bending resistance of composite beam tests The plastic bending resistance of a composite beam for partial shear connection is determined from a plastic stress distribution in the cross-section. The concrete compression force is in equilibrium with the shear forces introduced by the headed studs and defines the plastic stress block in the concrete. The plastic stress distribution in the steel section is calculated from the equilibrium of axial forces. The equilibrium condition for moments gives the plastic bending resistance of the cross-section. 
The accurate prediction of the concrete compression force is a precondition for the analysis of the plastic bending resistance. For ductile shear connectors and degrees of shear connection higher than the minimum degree of shear connection, a plastic shear force distribution is allowed for computations. In this case, each headed stud is considered to introduce a force equal to its shear resistance.

For the following comparisons, the plastic bending resistance $\left(M_{\mathrm{PL}}\right)$ is calculated assuming the shear resistance of headed studs obtained in push-out tests, as shown in Table 2, and the predicted shear resistances according to Equations 6-14. A comparison of the predicted bending resistances with the ultimate moment of the tests $\left(M_{\mathrm{u}}\right)$ is shown in Figure 8 .

Applying the shear resistance of the studs obtained from push-out tests, the calculated plastic bending resistance of the beam shows good agreement with the beam results. For beam test 2-04, no corresponding push test with pre-punched decking was conducted. According to Konrad (2011) and the push-out tests reported by Eggert et al. (2014), a 10\% reduction of the shear resistance compared with through-deck welded studs is assumed when holes are provided in the decking compared with through-deck welded studs as in push-out test 2-04, shown in Table 2. With these shear resistances, the correction factor according to EN 1990 (DIN, 2010a) for the bending resistance is $b=0.96$. In comparison with the analysis using calculated shear resistances according to EN 1994-1-1 (DIN, 2010b), Konrad (2011) or Nellinger (2015), the largest coefficient of variation, $V_{\delta}=0.08$, and the smallest coefficient of correlation, $R=0.92$, are obtained. The calculated bending resistance differs especially for beam test $2-03$, where the bending resistance is over-predicted by $20 \%$. A possible reason for this could be reduced welding quality when welding the studs

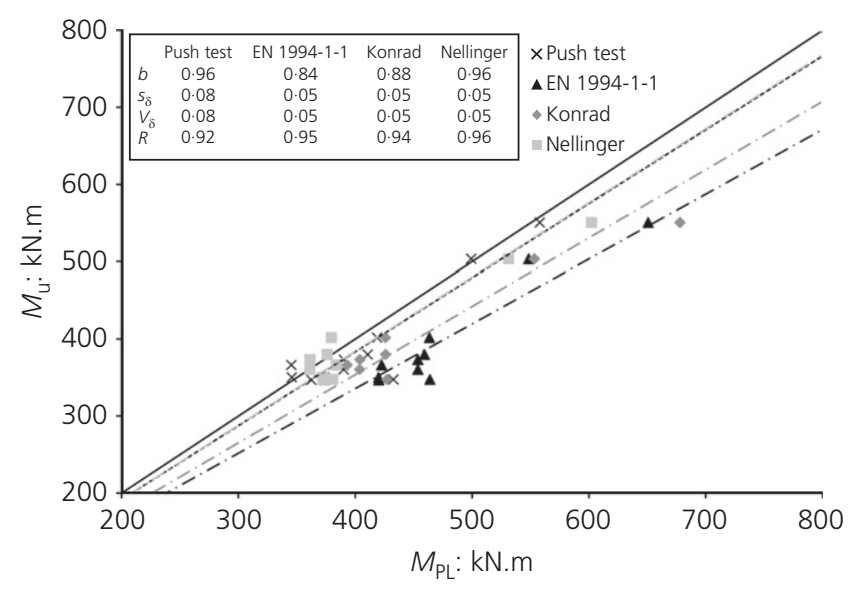

Figure 8. Comparison of experimental ultimate moment $\left(M_{\mathrm{u}}\right)$ with predicted plastic bending resistance $\left(M_{\mathrm{PL}}\right)$ according to the approaches of EN 1994-1-1 (DIN, 2010b), Konrad (2011) and Nellinger (2015) for the stud shear resistance through the decking (see Figure 7), although no stud failure was observed in the test. It is more likely that rib pry-out failure occurred. The shear resistance assumed in the computations was obtained from a push test with $125 \mathrm{~mm}$ long studs, which gives an embedment depth of 3.5 diameters, but in the beam test only $100 \mathrm{~mm}$ long studs were used, giving an embedment depth of $2 \cdot 2$ diameters. With deeper steel decking, rib pry-out was observed for an embedment depth of 2.4 diameters. Therefore, the shear resistance of the studs in the beam tests was probably smaller than the resistance obtained from the push-out tests. The over-estimation of the shear resistance likely explains the over-prediction of the bending resistance for beam 2-03.

The largest over-estimation of beam bending resistance was observed by considering the shear resistance of the studs according to EN 1994-1-1 (DIN, 2010b). The correction factor was only $b=0 \cdot 84$. The over-estimation of the bending resistance of the beams corresponds to over-estimation of the shear resistance of headed studs in push-out tests.

Using the shear resistance according to Konrad (2011), the correction factor is $b=0 \cdot 88$. In this case, specimens 2-03 and 2-10 are over-predicted. Both tests used pairs of studs; for specimen 2-10, rib pry-out failure was confirmed and its occurrence was likely for specimen 2-03. This correlates to the evaluation of the push-out tests, were the shear resistance for rib pry-out was also over-estimated. For the small embedment depth of the head of the stud in the beam tests, this failure mode more likely occurs for pairs of shear connectors. Accordingly, the results of the statistical analysis according to EN 1990 (DIN, 2010a) improve significantly if tests 2-03, 2-04 and 2-10 are not considered. The correction factor for the bending resistance of the remaining seven tests is then $b=0.91$, the coefficient of variation $V_{\delta}=0.02$ and correlation $R=0.99$. For six of the tests, Equation 11 for studs in an unfavourable position was used. This equation was developed for throughdeck welded studs, but five of the tests had pre-punched decking. Therefore, the results would further improve if the reduction for pre-punched decking given by $k_{\mathrm{w}}=0.9$ had been applied for these tests.

Using the shear resistance according to Nellinger (2015), the bending resistance is predicted even better than using tested shear resistances. The correction factor for the bending resistance is $b=0.96$ with a variation of $V_{\delta}=0.05$ and a correlation of $R=0.96$. In particular, the best result was obtained for specimen 2-03 because the predicted shear resistance assumed rib pry-out failure.

Evaluation of the plastic bending resistances confirmed that the procedure of EN 1994-1-1 (DIN, 2010b) is unsafe for the investigated modern forms of shear connection. Significantly better results are obtained with the more recent approaches proposed by Konrad (2011) and Nellinger (2015). 


\subsection{Shear stud resistance in composite beam tests}

The results of evaluation of beam plastic bending resistance correspond to the push test results. However, the comparison of bending resistances only allows rough conclusions on the shear resistance of studs. To obtain a better comparison of the shear resistance of headed studs with the prediction, the shear resistance must be calculated from beam test results.

For each beam, a diagram of the plastic bending resistance for partial shear connection can be calculated from the crosssection geometry and the measured material strengths. From such a diagram, the bending resistance of the test can be used to determine the effective degree of shear connection. This gave values between $13 \%$ (for specimen 2-09) and 35\% (for specimen 2-04). These values can then be transferred into an average load per shear connector when assuming plastic behaviour of the shear interface.

However, this average load per stud differs to the maximum shear resistance per stud. Non-linear analysis of the conducted beam tests showed that the shear force obtained from realistic load-slip curves, as shown in Figures 2(a) and 3(a), was about $10 \%$ smaller than the shear force calculated from a plastic force distribution using the ultimate force $P_{\mathrm{Rm}}$. This percentage may vary for other load cases, such as a uniform load distribution. To estimate the ultimate bearing capacity per stud $\left(P_{\mathrm{Rm}}\right)$, the shear forces determined from the bending resistance of the tests were increased by $10 \%$. The shear resistances are compared with the predicted values in Figure 9 and the figure confirms the results of the evaluation of push test results.

For the model in EN 1994-1-1 (DIN, 2010b), the results were almost equal when push-out test results or beam test results were evaluated. The predicted shear resistance was unsafe for the investigated modern forms of sheeting by about $45 \%$. Due to the shorter studs in the beam tests, the reduction factor

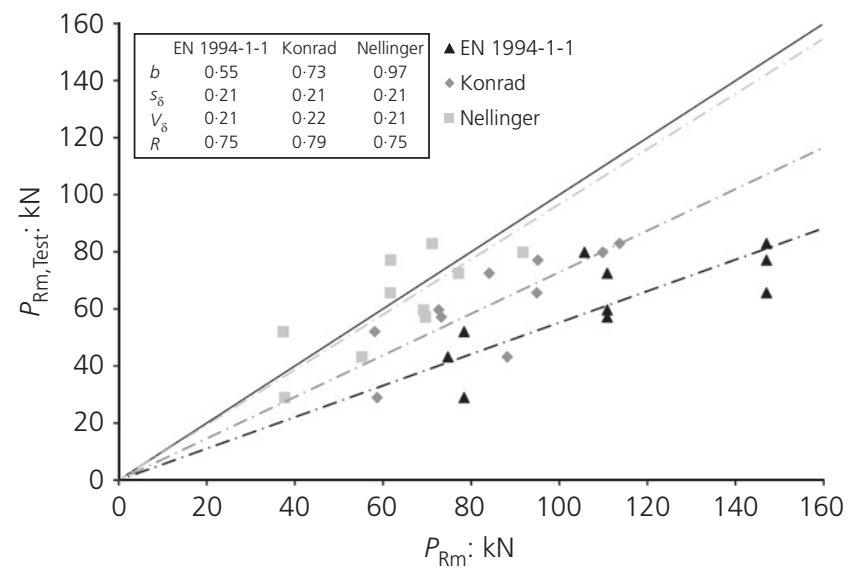

Figure 9. Comparison of shear resistance calculated from beam tests with predicted shear resistances according to the approaches of EN 1994-1-1 (DIN, 2010b), Konrad (2011) and Nellinger (2015) $k_{\mathrm{t}}$ according to Equation 8 was always decisive. This means that neither $k_{\mathrm{t}}$ nor the limitation $k_{\mathrm{t}, \max }$ are safe for modern applications.

The model of Nellinger (2015) gave almost equal results when evaluating the shear resistance in push tests and beam tests. The predicted shear resistances were very close to the experimental results.

For the model of Konrad (2011), the correction factor for the mean shear resistance $(b)$ decreased from 0.78 in the push tests to 0.73 in the beam tests, but the coefficient of variation was strongly improved to $V_{\delta}=0 \cdot 22$. The shear resistance of studs for beams 2-03 and 2-10 was especially over-estimated. In both these cases the over-prediction is related to rib pry-out failure if using pairs of studs. If only beam tests with single studs per rib are considered, the results for the remaining seven tests improve to $b=0.76, V_{\delta}=0.08$ and $R=0.83$, and these results further improve if the influence of the welding method is considered. However, the required correction of the mean shear resistance is significantly larger than for the evaluation of the push test results. The major difference between the beam tests and the push tests was the stud height. In both cases the required ratio $h_{\mathrm{sc}} / h_{\mathrm{p}} \geq 1.56$ was well satisfied. However, the $100 \mathrm{~mm}$ long studs were the smallest possible considering the $2 \times$ diameter criterion of clause $6 \cdot 6 \cdot 5 \cdot 8(1)$ of EN 1994-1-1 (DIN, 2010b), which was not even satisfied for beams 2-05 to 2-07 with $22 \mathrm{~mm}$ diameter studs.

\subsection{Ductility of the shear connection}

Using the shear resistances $\left(P_{\mathrm{Rm}}\right)$ calculated from the beam test results at ultimate load, the degree of shear connection in the tests was found to be between 14 and 39\%. These values are smaller than the requirements of EN 1994-1-1 (DIN, 2010 b) given by the lower cut-off of $40 \%$.

Figure 10 shows the bending resistance of the tests at $6 \mathrm{~mm}$ end slip plotted versus the degree of shear connection in comparison with the predicted plastic bending resistance. All beam tests except specimen 2-04 reached more than $95 \%$ of the predicted plastic bending resistance. Therefore, the requirements used to develop the current formulae for the minimum degree of shear connection (Aribert, 1997) were satisfied in most cases.

The test results correspond well with the correlation function for beams with profiled sheeting given by Equation 1. For specimens 2-01 to 2-08, Equation 1 requires a degree of shear connection of $26 \%$ and for specimens 2-09 and 2-10 a degree of shear connection of $29 \%$. None of the tests with a smaller degree of shear connection failed to reach the required $95 \%$ bending resistance at $6 \mathrm{~mm}$ slip. It was observed that it was not necessary to consider the cut-off value of $40 \%$ shear connection in order to prevent failure of the shear interface at ultimate limit state. 


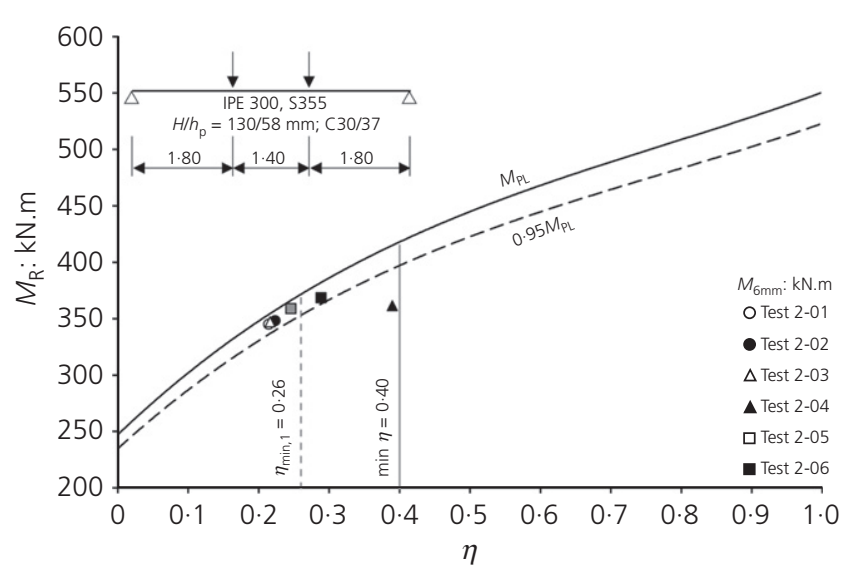

(a)

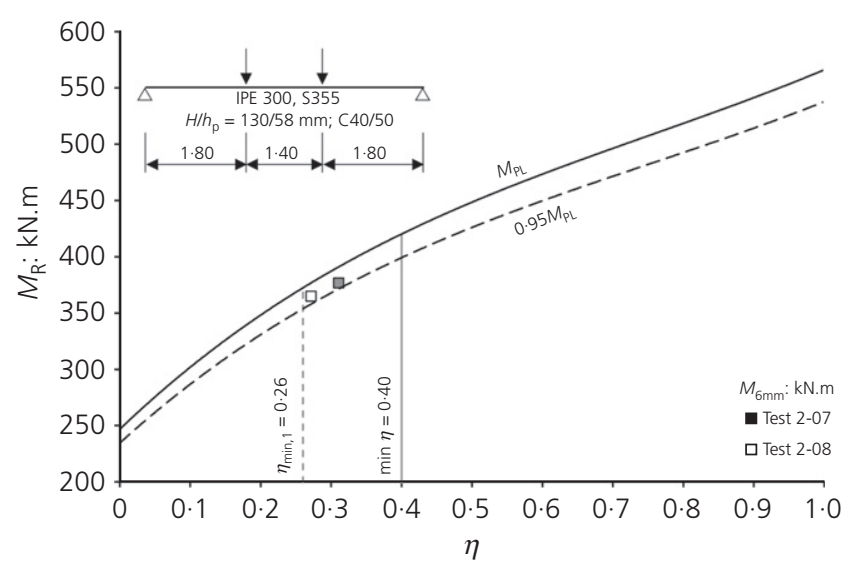

(b)

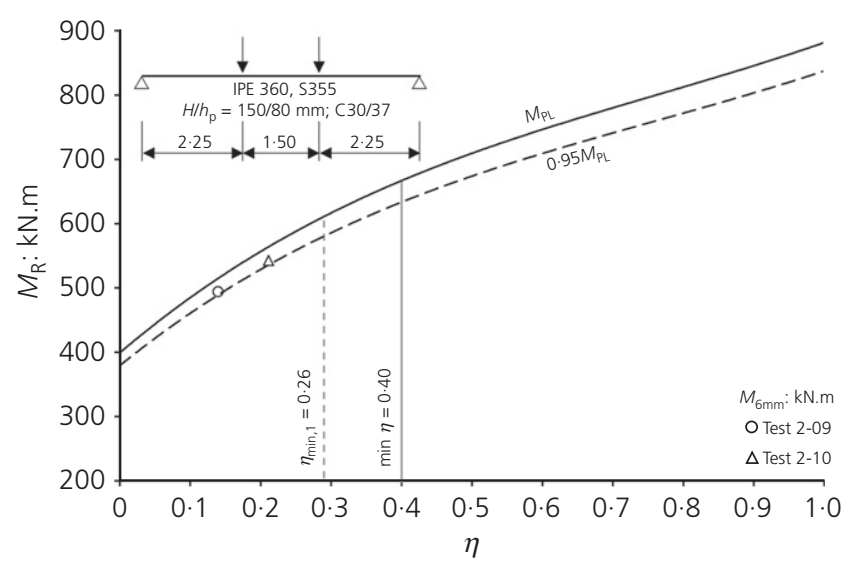

(c)

Figure 10. Comparison of test moment at $6 \mathrm{~mm}$ end slip with the plastic bending resistance and degree of shear connection: (a) beams 2-01 to 2-06; (b) beams 2-07 and 2-08; (c) beams 2-09 and 2-10

\section{Conclusions}

The results of ten composite beam tests have been presented. Based on evaluation of the plastic bending resistance, the degree of shear connection was determined to be $13 \%$ to $39 \%$, which is smaller than the minimum requirement of EN 1994-1-1 (DIN, 2010b). The beam tests showed that there was no failure of the shear interface at ultimate load. Furthermore, nine of the ten tests reached more than $95 \%$ of the plastic bending resistance at $6 \mathrm{~mm}$ end slip, meaning that the definition of the minimum degree of shear connection used by Aribert (1997) was satisfied. Accordingly, plastic design procedures were applicable to predict the bending resistance of the beam tests. However, accurate prediction of the shear resistance of headed studs is a precondition.

The shear resistance of headed studs was evaluated based on push-out and beam test results. The tests investigated modern practice in composite construction, such as shallow but slender deck ribs, deep deck ribs and studs with the minimum allowed embedment depth.

A comparison of the test results with the mean shear resistances calculated according to EN 1994-1-1 (DIN, 2010b) showed that the formulae are unsafe for these modern cases. The influence of the stud position in narrow deck ribs and new concrete failure modes were responsible for the over-estimation. Significantly better results were obtained when comparing the results with the mean shear resistances calculated using the methods of Konrad (2011) and Nellinger (2015). Both methods were accurate for shear studs showing rib punch-through failure. However, the formulae of Konrad over-estimated the resistance for rib pry-out failure, which was not considered in the development of the new reduction factors. This failure mode leads to a significantly smaller shear resistance, especially when pairs of studs are used. The formulae of Nellinger were developed with regard to this new failure mode and resulted in more accurate predictions of the shear resistance.

The results of this study show the need to revise the rules of EN 1994-1-1 (DIN, 2010b) for the shear resistance of headed studs in profiled sheeting, especially for modern application cases. The alternative methods of Konrad (2011) and Nellinger (2015) may complement the current rules of EN 1994-1-1 (DIN, 2010b) to accurately predict the shear resistance of headed studs in the presence of modern forms of profiled sheeting.

\section{Acknowledgements}

The research leading to these results was part of a common project of the Steel Construction Institute, University of Stuttgart, University of Luxembourg, University of Bradford and ArcelorMittal. The project received funding from the European Community's Research Fund for Coal and Steel (RFCS) under grant agreement RFSR-CT-2012-00030.

\section{REFERENCES}

Aribert JM (1997) Analyse et formulation pratique de l'influence de l'acier du profile sur le degré minimum de connexion partielle d'une poutre mixte. Construction Métallique 3: 39-55 (in French).

DIN (Deutsches Institut für Normung) (2010a) EN 1990: Eurocode: Basics of structural design; German version EN 1990: 2002+A1:2005+A1:2005/AC. DIN, Berlin, Germany. 
Structures and Buildings

Volume 171 Issue SB1
Short-span composite beam tests

to evaluate stud resistances

Nellinger, Eggert, Kuhlmann, Odenbreit

and Obiala
DIN (2010b) EN 1994-1-1: Eurocode 4: Design of composite steel and concrete structures - Part 1-1: General rules and rules for buildings; German version EN 1994-1-1: 2004+AC:2009. DIN, Berlin, Germany.

Eggert F, Nellinger S, Kuhlmann U and Odenbreit C (2014) Push-out tests with modern deck sheeting to evaluate shear connector resistances. Proceedings of the 7th European Conference on Steel and Composite Structures, Napoli, Italy (Landolfo R and Mazzolani FM (eds)). European Convention for Constructional Steelwork, Brussels, Belgium, pp. $519-520$

Konrad M (2011) Tragverhalten von Kopfbolzendübeln in Verbundträgern bei senkrecht spannenden Trapezprofilblechen. University of Stuttgart, Stuttgart, Germany (in German).
Lungershausen H (1988) Zur Schubtragfähigkeit von Kopfbolzendübeln. Ruhr-Universität Bochum, Bochum, Germany (in German).

Nellinger S (2015) On the Behaviour of Shear Stud Connections in Composite Beams with Deep Decking. University of Luxembourg, Luxembourg, Luxembourg.

Nellinger S, Odenbreit C and Lawson RM (2014) Push-out tests with modern deck sheeting and realistic transverse loading. Proceedings of the 12th International Conference on Steel, Space and Composite Structures, Prague, Czech Republic (Wald F and Chiew SP (eds)). CI-Premier Pte Ltd, Singapore, Republic of Singapore, pp. 285-294.

Roik K, Hanswille G, Cunze A and Lanna O (1989) Report on Eurocode 4, Clause 6.3.2: Stud Connectors. Ruhr-Universität Bochum, Bochum, Germany.

\section{How can you contribute?}

To discuss this paper, please email up to 500 words to the editor at journals@ice.org.uk. Your contribution will be forwarded to the author(s) for a reply and, if considered appropriate by the editorial board, it will be published as discussion in a future issue of the journal.

Proceedings journals rely entirely on contributions from the civil engineering profession (and allied disciplines). Information about how to submit your paper online is available at www.icevirtuallibrary.com/page/authors, where you will also find detailed author guidelines. 